\title{
La ciudad como escenario de innovación docente. El caso de la pasarela urbana en las enseñanzas de Moda
}

\author{
Laura Luceño Casals ${ }^{1}$ | Pablo Campos Calvo-Sotelo ${ }^{2}$ \\ Recibido: 03-06-2020 | en su versión final: 16-10-2020
}

Resumen

\begin{abstract}
Las ciudades constituyen una realidad histórica y patrimonial de ingente valor cultural. Fruto de tal bagaje, se erigen en candidatas para aportar recursos de gran potencial formativo para instituciones académicas. Mediante planificaciones estratégicas, es factible idear acciones que compaginen la innovación docente con el disfrute de determinados elementos urbanístico-arquitectónicos, de modo que se generen escenarios donde converjan pedagogía y patrimonio, y ambos componentes resulten reforzados en reciprocidad. Partiendo de unas reflexiones acerca de la innovación en modalidades de Enseñanza/Aprendizaje, el presente texto tiene como objetivo centrarse en dos tipos de sinergias universitario-urbanas, llamadas a intensificar la referida convergencia: adscripciones y participaciones. Si bien las primeras son relevantes, el artículo se centra en el caso específico de las segundas, asociándolas al marco educativo de las enseñanzas de Moda. La metodología estructura un estudio comparado de las pasarelas urbanas, contemplándolas como lugares donde se lleva a cabo una exposición creativa de resultados del aprendizaje por parte de los alumnos. A tal fin, y siguiendo un modelo teórico común, se analizan los siguientes casos: Amberes (barrio de Eilandje), Madrid (Teatro Real, Conde Duque y Matadero), Savannah (Museo de Arte), Milán (Teatro Vetra), Cannes (Rue d'Antibes), Terrassa (Teatre Alegria), Florencia (Via Tornabuoni) y Nueva York (Greenwich Village). Todos ellos son ejemplos ilustrativos de la exitosa y original combinación de dinámicas de innovación pedagógica con el valor del patrimonio urbanístico-arquitectónico de cada emplazamiento. Tras la lectura transversal de los referidos casos recientes, se extraen conclusiones proactivas, con el propósito de que puedan inducir a estrategias de valor equivalente en otras ciudades, y en áreas de conocimiento alternativas.
\end{abstract}

Palabras clave: universidad; ciudad y creatividad; innovación docente; desfile de moda

Citación

Luceño, L. y Campos Calvo-Sotelo, P. (2021). La ciudad como escenario de innovación docente. El caso de la pasarela urbana en las enseñanzas de Moda, ACE: Architecture, City and Environment, 15(45), 9486. DOI: http://dx.doi.org/10.5821/ace.15.45.9486

\section{The City as a Scenario for Teaching Innovation. The Case of the Urban Catwalk in Fashion Education}

Abstract

\begin{abstract}
Cities constitute a historical and heritage reality of enormous cultural value. As a result of this baggage, they become candidates to provide resources with great educational potential for academic institutions. Through strategic planning, it is feasible to devise actions that combine teaching innovation with the enjoyment of certain urban-architectural elements, so that scenarios are generated, where pedagogy and heritage converge, and both components are reinforced. Starting from some reflections on innovation in Teaching/Learning modalities, the goal of this text is to focus on two types of university-urban synergies called to intensify the referred convergence: secondments and participations. Although the former is relevant, the article focuses on the specific case of the latter, associating them to the specific educational framework of the teaching of Fashion. The methodology structures a comparative study of urban catwalks, considering them as places where a creative exhibition of learning results by students is carried out. To this end, and following a common theoretical model, the following cases are analysed: Antwerp (Eilandje neighborhood), Madrid (Teatro Real, Conde Duque and Matadero), Savannah (Art Museum), Milan (Teatro Vetra), Cannes (Rue d'Antibes), Terrassa (Teatre Alegria), Florence (Via Tornabuoni) and New York (Greenwich Village). All of them are illustrative examples of the successful and original combination of dynamics of pedagogical innovation with the value of the urban-architectural heritage of each site. After the cross-sectional reading of the recent cases, proactive conclusions are drawn, so that they can induce strategies of equivalent value in other cities, and in alternative areas of knowledge.
\end{abstract}

Keywords: university; city and creativity; teaching innovation; fashion runway

Doctora en Moda, Profesora del Centro Superior de Diseño de Moda de Madrid, CSDMM, Universidad Politécnica de Madrid, UPM (ORCID: 0000-0003-0479-308X), 2 Doctor Arquitecto, Catedrático de Composición Arquitectónica, Universidad CEU-San Pablo (ORCID: 0000-0002-9534-3908, WoS ResearcherID: L-3111-2014). Correos de contacto: laura.luceno@telefonica.net, utoplan@telefonica.net 


\section{Introducción: la ciudad como escenario de innovación para las universidades}

Las universidades atraviesan una coyuntura de cambio de paradigma. Esta dinámica global se ha puesto de relevancia singularmente en el Viejo Continente, regido por el Espacio Europeo de Educación Superior (EEES), cuyo germen tuvo lugar el 25 de mayo de 1998 con la "Declaración de La Sorbona". Este documento ya avanzaba el trascendental cambio en el que se enmarca el presente artículo: "Debemos a nuestros estudiantes y a la sociedad en su conjunto un sistema de educación superior que les ofrezca las mejores oportunidades para buscar y encontrar su propio ámbito de excelencia”.

Procede expresar una síntesis de los rasgos del EEES. Su creación implicó una transformación estructural de títulos, y una apuesta por la calidad y la innovación. Ambos conceptos, de gran trascendencia, son plenamente extrapolables al escenario mundial, y ambos guardan relación con la dimensión urbanístico-arquitectónica: "Las directrices de los últimos años derivadas del proyecto europeo de educación superior (EEES), genéricamente denominado como 'Plan Bolonia', suscitan nuevos y profundos interrogantes sobre el devenir de nuestras universidades, funciones y organización, y lógicamente de sus concepciones y usos espaciales” (Hernández Díaz, 2014, p. 85).

Dichas cualidades, calidad e innovación, deben traspasar los límites del recinto académico, impregnando el entorno (que frecuentemente es plenamente ciudadano) (Bellet y Ganau, 2006). Históricamente, las universidades han sido promotoras de innovación, en las diversas acepciones del término. Cuando nace un complejo docente, se activa una energía centrífuga de recualificación sociocultural, económica y urbanística de su entorno.

Calidad e innovación han supuesto, en paralelo, la reinvención de las modalidades de Enseñanza/Aprendizaje, sustentada en criterios como el énfasis en la adquisición autónoma de competencias por el alumno, y la entrada en escena de metodologías alternativas a la tradicional lección magistral, las cuales necesitan espacios ad hoc. Aun manteniendo parcialmente las aulas tradicionales, las corrientes de progreso obligan a imaginar otros lugares, que alojen los renovados formatos pedagógicos.

Por todo ello, el impulso a las instituciones de Educación Superior inducido por el EEES ha de traducirse a una análoga renovación urbanística y arquitectónica. Tan importante aspecto afecta a la relación universidad/ciudad, dimensión que arma los contenidos del presente texto.

En este punto, es preciso subrayar que las universidades suman a sus dos misiones esenciales (docencia e investigación) una tercera, que incide en el compromiso con la sociedad: "Estas palabras enlazan con claridad con ideas actuales sobre la 'tercera misión ', tal y como hoy la entendemos, ya que se orienta, sobre todo, a la necesidad de saber aplicar la ciencia, es decir, transferir el conocimiento a la sociedad, y poder responder a la demanda social de su tiempo" (Bueno, 2007).

Tal vocación exige reformular las sinergias humanas con el contexto; pero obliga a su vez a considerar las específicamente espaciales. Si la ciudad es el cuerpo construido de la sociedad, la universidad debe optimizar las referidas sinergias físicas, como herramienta de gran efectividad para incrementar su beneficioso impacto.

\footnotetext{
1 Declaración de La Sorbona: Declaración conjunta para la armonización del diseño del Sistema de Educación Superior Europeo. La Sorbona, París, 25 de mayo de 1998.
}

ACE, 15 (4.5) CC BY-ND 3.0 ES | UPC Barcelona, España | La ciudad como escenario de innovación docente. El caso de la pasarela urbana en las enseñanzas de Moda. DOI: $\underline{\text { http://dx.doi.org/10.5821/ace.15.45.9486 }}$ 


\section{Innovación docente y espacio físico en la Educación Superior}

En una de sus bases, el referido EEES estableció la promoción de modalidades innovadoras de Enseñanza/Aprendizaje, induciendo con ello la mutación de los formatos tradicionales (lección magistral) hacia dinámicas progresistas centradas en el alumno. Este traslado del centro gravitatorio de la docencia está llamada a desencadenar una respuesta trascendente en el alumno: la motivación, verdadera clave en su proceso formativo. Innovar conlleva una profunda transformación cultural, que conduzca a los profesores a transitar desde una transmisión unilateral del conocimiento, hacia otra multilateral, abierta y creativa. En dicho tránsito, es imprescindible valorar la metamorfosis que debe experimentar el entorno físico; en otras palabras, la educación devenga formas espaciales (Campos, y Luceño, 2018).

Si se efectúa una mirada al pasado no muy distante, las pedagogías del ayer pivotaban en torno al aula convencional, caracterizada por la rigidez espaciotemporal: "La organización del espacio, el tiempo y el control de los cuerpos siguió el método de organización propuesto, con el docente en lugar privilegiado, y el aprendizaje fundido en la enseñanza." (Pineau, Dussel y Caruso, 2001, p. 46).

Pero la contemporaneidad introdujo nuevas miradas. No son pocos los autores internacionales que plantean desde hace tiempo enfoques vanguardistas en este tema. En un reciente trabajo, los arquitectos Fielding y Nair, especialistas en espacios educativos, manifestaban: "Bajo el nuevo paradigma del aprendizaje, estamos frente a un modelo donde estudiantes diferentes (de diversas edades) aprenden cosas diferentes, de personas diferentes, en lugares diferentes, de modos diferentes y en tiempos diferentes" (Nair, y Fielding, 2005, p. 19). Se invita a interiorizar las dinámicas de Enseñanza/Aprendizaje rechazando que estén domiciliadas en un único tipo de enclave; y centrar dichas dinámicas en el alumno. Uno de los objetivos de la innovación docente es potenciar las capacidades del profesorado para implementar nuevos formatos de transmisión de conocimientos.

Apelando a la imaginación como actitud que invada todas las esferas pedagógicas, los docentes podrán evolucionar desde su vetusto papel como meros "transmisores" a una faceta más creativa, como "inductores" de cambios positivos. Y asumir que la finalidad básica de la labor profesoral es incrementar la subrayada motivación del alumno para con su formación integral, verdadera misión de las universidades. Todo ello exige considerar el decisivo rol de los espacios físicos, como partícipes directos que propician el contacto humano, verdadero aval de la calidad didáctica. La consecuencia de tal asunción está aflorando como cambio de paradigma, compaginando espacio, tiempo y función, y caracterizándose por la disolución de los límites espaciotemporales. El aula se libera del encorsetamiento de las cuatro paredes, para abrirse al entorno, lo que implica una dinámica vanguardista de involucración del contexto social (Castro, Rodríguez y Urteaga, 2016).

Semejantes consideraciones afectan a cualquier área de conocimiento, pero han dejado testimonios de relevancia en el campo de las enseñanzas de Moda, las cuales protagonizan este artículo. El aprendizaje que desarrolla el futuro diseñador es una versión aplicada de la formación humana, compartiendo con ella que se erige en una actividad trascendente, que camina de la mano de la evolución social. Por ello, la enseñanza de la Moda está supeditada al cambio. Aprender Moda con solvencia supone interiorizar un profundo sentido de adaptación a dicho cambio, como asimismo al entorno. Y puesto que el entorno es la ciudad, se ha podido comprobar el interés resultante de activar estrategias de innovación que integren al hecho urbano como partícipe directo, tal y como reflejan las experiencias que aquí se recogen.

ACE, 15 (4.5) CC BY-ND 3.0 ES | UPC Barcelona, España | La ciudad como escenario de innovación docente. El caso de la pasarela urbana en las enseñanzas de Moda. DOI: $\underline{\text { http://dx.doi.org/10.5821/ace.15.45.9486 }}$ 


\section{El potencial formativo del patrimonio urbanístico-arquitectónico}

El contexto donde los seres humanos se desenvuelven habitualmente es la ciudad. Cabe entenderla como un hecho complejo, físico y cultural, que influye en la cotidianeidad de la comunidad que la construye y disfruta. Sobre esta dualidad físico-cultural, anotaba Johnson: "Vivimos en y a través de nuestras continuas interacciones con entornos que son tanto físicos como culturales" (Johnson, 2015). Interiorizada como escenario del habitar, se define como realidad construida y receptáculo del habitar y el devenir de las generaciones: "La ciudad, realidad y símbolo cultural de los procesos que dan sentido al habitar, al construir un lugar - no solo en sentido físico - implica una suma de tiempos y paradigmas que constituyen y dan sentido a formas de vida y realidades cotidianas" (Pérez y González, 2010, p. 123).

Como tal contexto vital, la urbe enriquece dualmente el conocimiento humano: se aprende en ella y se aprende de ella. Lo primero pone sobre la mesa unas oportunidades ingentes: la ciudad educa, cristalizando como todo un recurso formativo. Y lo hace en dos planos básicos: en el plano funcional (pues habitualmente concentra en su seno un número destacado de instituciones dedicadas a la formación humana, en sus diversos niveles y etapas, desde la escolar a la universitaria); y en el plano patrimonial (al aportar un ingente valor, compuesto por piezas arquitectónicas, estructuras urbanísticas, espacios libres y obras artísticas) (Ortiz, 2013). Una doble acción singularmente relevante en la esfera de la Moda. Respecto a lo segundo, las instituciones educativas pueden desarrollar dinámicas para que los alumnos adquieran un conocimiento directo y profundo de su realidad (Aranguren, 2003), (Carreras, 1983).

En diversas aportaciones internacionales se ha puesto de manifiesto el bagaje educativo de la ciudad (Silvera y Sacker, 2013), (Figueras, 2007), y el positivo impacto derivado de la interacción entre los jóvenes y el entorno ciudadano: "la experiencia de ciudad que viven a nivel local, o de la urbe en general, les permite un proceso de crecimiento, de formación, ya sea por los elementos urbanos que objetivan en su arte, o por la utilización de los espacios público para ejercitarse en el oficio o sencillamente para lograr presencia pública" (Cubides, y Salinas, 2010, p. 18). Su potencial formativo es un valor poliédrico, que ha generado iniciativas tan sugerentes como la de "Cittáslow" (Radstrom, 2011), así como es uno de los cimientos del movimiento "Ciudades Educadoras" (Asociación Mundial de Ciudades Educadoras, 1990). En paralelo, la asunción de las ciudades como contextos formativos ha impulsado iniciativas como la "UNESCO Global Network of Learning Cities" centrado en el Aprendizaje a lo Largo de Toda la Vida en los entornos urbanos. La iniciativa de la UNESCO establece, entre sus principios, la voluntad de utilizar los centros culturales como sedes educativas, aunando en su seno cultura, arte y aprendizaje.

En suma, valorar el concurso de la realidad urbanístico-arquitectónica de la ciudad como recurso educativo de largo recorrido vital entronca directamente con el contenido esencial del presente artículo. Pero dicho contenido se nutre en paralelo de una importante circunstancia: la Moda se entiende histórica y socialmente como un hecho urbano, razón por la cual las experiencias de innovación docente, que se analizan siguiendo una metodología común en el presente texto, cobran mayor justificación si cabe.

\section{La Moda, fenómeno urbano}

Asumido el aporte formativo inherente al patrimonio de la ciudad, es pertinente engarzarlo con la disciplina de la Moda. La razón es que, en efecto, la Moda es un fenómeno esencialmente urbano: "Consecuentemente, la moda deber ser contemplada desde distintos ángulos, como una historia de la decoración y vestido del cuerpo, un lenguaje y juego irracional, una expresión de sexualidad y un

ACE, 15 (4.5) CC BY-ND 3.0 ES | UPC Barcelona, España | La ciudad como escenario de innovación docente. El caso de la pasarela urbana en las enseñanzas de Moda. DOI: http://dx.doi.org/10.5821/ace.15.45.9486 
hecho económico y una experiencia urbana" (Finkelstein, 1996, p. 7). Un fenómeno que se ha proyectado sobre las ciudades en forma de espectáculo (Williams y Egenhoefer, 2017). A ello se suma que desde el siglo XIX, los enclaves metropolitanos más significativos han albergado comercios de Moda, impregnando con su personalidad no pocas calles e itinerarios cargados de simbolismo del alto nivel social (Benjamin, 2005). Esta interpretación del vestir en términos de naturaleza ciudadana tiene más de un siglo de antigüedad, como recogen las aportaciones de teóricos como Simmel (Simmel, 1923). Simmel sostuvo que debía asimilarse la Moda como una suerte de elemento de ingreso al lugar donde vive gran parte del entorno social, esto es, la metrópoli (De Simone, 2012). Se señaló asimismo que uno de los rasgos de la Moda es su dimensión estética, en la vida y la sociedad, acentuada por la vida urbana. Por tanto, tales testimonios avalan que tiene sentido engarzar ciudad, Moda y expresión estética, cuestión que cimenta el corpus central del presente texto.

Consecuentemente, se entiende justificado exponer las experiencias de innovación docente que se han llevado a cabo en las enseñanzas de Moda, pues siempre han existido sinergias conceptuales entre Moda y urbe. A ello cabe añadir un conjunto de características que comparten Arquitectura y Moda, en clave compositiva, que refuerzan más sus vínculos: forma, color, transparencia, volumen o luz, así como otros que comparten las pasarelas con el dinamismo inherente a las urbes: movimiento, desarrollo espacial o perfil escenográfico, entre otros. Y la dimensión estética: "así como la ciudad genera formas de sociabilidad, también es un lugar que hace emerger formas estéticas” (Remy, 2012, p. 38). Una de esas formas estéticas es, incuestionablemente, la Moda, como producto social y realidad formal surgida de un impulso creativo de diseño.

Todas estos aspectos tipológico-espaciales sirven para avalar la conexión singular existente entre el patrimonio urbano y las pasarelas de Moda, cuyos casos de estudio son investigados bajo tal prisma a lo largo del texto.

\section{Las sinergias universitario-urbanas}

Las universidades pueden contar con el potencial formativo de la ciudad como valioso acompañante a lo largo de su evolución, en clave de innovación docente. El contexto urbano suministra un escenario de gran versatilidad para enriquecer los procesos de Enseñanza/Aprendizaje, cuando de alcanzar la formación integral del estudiante se trata. A sensu contrario, las instituciones docentes son destacadas actrices en la recualificación socio-urbana: la emergencia dentro del entramado metropolitano de sus actividades promueve el progreso, desencadenando en torno a sí regeneraciones socioculturales y espaciales.

La ciudad dispone habitualmente de un conjunto de valores patrimoniales y equipamientos que aportan a las universidades recursos culturales, funcionales y artísticos de potencial impacto pedagógico; así, puede favorecer su enriquecimiento, a partir de las sinergias planteadas. Tratar de rentabilizar dichas sinergias es un objetivo deseable, pues pone en relación con dos realidades (universitaria y urbana) que en excesivas ocasiones no interactúan debidamente; tal carencia recomienda acometer reflexiones que reinventen las sinergias entre ellas (Izquierdo, 2005). El refuerzo las mismas ha sido motivo de investigaciones de perfil teórico (Casariego y Macías, 1989), y asimismo de análisis de casos específicos, como el relativo a la Comunidad de Madrid, que se cita puesto que algunas experiencias de innovación docente en Moda han tenido lugar en ese ámbito territorial (Oliva, y Sánchez, 2016).

Los equipamientos de la ciudad (en especial, los culturales), suministran valores como constructores de sentimientos de identidad entre los habitantes, siendo las comunidades universitarias una parte destacada de los mismos (Franco y Zabala, 2012). El patrimonio pone a disposición de las comunidades académicas toda su valía histórica, cultural y artística. Un valor que se hace presente

ACE, 15 (4.5) CC BY-ND 3.0 ES | UPC Barcelona, España | La ciudad como escenario de innovación docente. El caso de la pasarela urbana en las enseñanzas de Moda. DOI: http://dx.doi.org/10.5821/ace.15.45.9486 
tanto mediante piezas arquitectónicas, como en sectores de la estructura urbanística, espacios libres y ciertos elementos de paisaje natural. El patrimonio proyecta conocimiento en sí mismo, pero en muchos casos se ofrece como escenario donde acoger modalidades de Enseñanza/Aprendizaje innovadoras; tal es el caso de alguna de las experiencias de formación de diseñadores de Moda que se recogen en este artículo.

Las sinergias universidad-ciudad podrían clasificarse en dos grandes tipologías: adscripciones y participaciones. En las primeras, la universidad sólo se suma externamente a las actividades alojadas en alguno de dichos equipamientos, impulsando esas mismas actividades en ellos desarrolladas (tal sería el caso de museos, centros cívicos y culturales, bibliotecas, u obras de teatro); en las segundas, la institución académica inserta algún uso propio en aquellos equipamientos que pertenezcan a la esfera municipal (como espacios libres, parques, obras arquitectónicas singulares, espacios feriales, instalaciones deportivas y, en general, cualquier equipamiento donde la institución docente pueda desarrollar acciones formativas propias). Uno de los elementos de mayor potencial pedagógico son los museos, razón por la cual sus vínculos con la universidad han dado lugar a estudios específicos (Riquelme-Quiñonero et. al., 2019). Como anticipo a cuanto se expondrá en relación con las experiencias de innovación docente en Moda, cabe señalar que IFEMA (recinto ferial de Madrid, en el que se organizan las Semanas de la Moda y las Ferias del sector como MOMAD), y el Museo del Traje se han comportado como destacables núcleos formativos de apoyo.

Finalmente, debe añadirse que las sinergias universitario-urbanas han de gestionarse con eficacia, siendo los convenios institucionales un sencillo, pero muy útil, instrumento que regula la beneficiosa utilización conjunta de los equipamientos.

\section{Herencia e innovación en la formación del diseñador de Moda: del aula convencional a las pasarelas urbanas}

El presente texto indaga en los rasgos innovadores inherentes a ciertas experiencias donde convergen Moda y ciudad; por ello, procede exponer ciertos rasgos propios de la formación de estos diseñadores. El diseño de Moda está cobrando gran relevancia en el panorama universitario español. Es un tipo de formación que incluye asignaturas y pedagogías muy diversas, y que requiere consecuentemente espacios diferentes, que permitan experiencias variadas de Enseñanza/Aprendizaje: desde una práctica en el taller de confección o patronaje, hasta un diseño por ordenador en el aula de infografía, pasando por el taller químico-textil, o una sesión en el plató fotográfico. Las diferentes enseñanzas del futuro diseñador de Moda convergen en una actividad vertebradora y con un potencial motivador incomparable: el desfile. La innovación educativa no siempre se traduce a la creación de una actividad inédita; en ocasiones, basta con ofrecer al estudiante una experiencia real, lo más profesionalizante posible. En ese sentido, la pasarela es el evento de la Moda por excelencia, fomenta la adquisición de conocimientos de forma autónoma por parte del estudiante, le obliga a tomar decisiones, así como a controlar múltiples aspectos como la imagen, la producción o la puesta en escena.

¿Por qué debe considerarse un formato pedagógico innovador el desfile de Moda realizado por los propios alumnos? Básicamente porque atesora varias virtudes. Por un lado, permite mostrar públicamente los resultados tangibles de la formación del alumno. Es una pauta propia de los grandes profesionales del sector; como consecuencia inducida por ello, recientemente el estudiante ha comenzado a trascender los límites del aula convencional para integrarse en la ciudad, estableciendo de este modo sinergias creativas con el patrimonio urbanístico-arquitectónico. Entre otros aspectos trascendentales en la presentación de una colección de Moda, cabe citar la elección de la ubicación del desfile en la metrópoli, la preferencia por una pieza patrimonial o por un espacio innovador, así como el diseño de la propia pasarela o la escenografía que la acompaña. En la pasarela, la

ACE, 15 (4.5) CC BY-ND 3.0 ES | UPC Barcelona, España | La ciudad como escenario de innovación docente. El caso de la pasarela urbana en las enseñanzas de Moda. DOI: http://dx.doi.org/10.5821/ace.15.45.9486 
Arquitectura y los espacios abiertos se incorporan a los ámbitos de exposición de los diseños de los estudiantes, para realzar y expresar valores, sumergiendo al espectador en una atmósfera meticulosamente calculada. La elección del lugar juega un papel clave en la construcción de imágenes, y en la consecuente transmisión de valores del desfile.

En suma, la innovación docente ha apostado por dar visibilidad a los resultados del aprendizaje de los alumnos. Las pasarelas urbanas, como acción pedagógica protagonizada por los estudiantes, han cobrado una creciente notoriedad social, y se han posicionado dentro de la ciudad: en las calles, en los teatros, en los museos, en edificios históricos..., activando sinergias creativas entre los valores del lugar patrimonial y la propia creatividad inherente al diseño de Moda de los discentes, generando experiencias vivenciales irremplazables.

\section{Los lugares de la ciudad como escenarios de innovación docente en Moda: expresividad, tipologías generales y especificidad de las pasarelas urbanas}

En epígrafes precedentes, se han argumentado los valores inherentes al potencial formativo de la ciudad, y las sinergias en su relación con la universidad. Pues bien, de la intersección de ambas cuestiones surge una multiplicidad de lugares dentro del tejido urbano, que atesoran una contrastada capacidad de erigirse en escenarios que acojan modalidades de Enseñanza/Aprendizaje alternativas a pautas convencionales, incentivándose con ello la creatividad y la expresividad. Antes de proceder a desglosar las tipologías concernientes a tales lugares, es oportuno reflejar, siquiera puntualmente, que la expresividad es otro de los aspectos que pueden compartir ciudad y Moda. Como señalaba Emilio Martín, evocando a Kracauer: "El conocimiento de las ciudades va unido al desciframiento de sus imágenes expresivas” (Martín, 2009, p. 3). Las pasarelas urbanas que se analizan en el presente texto son un claro ejemplo de tal expresividad, que se suma a la propia del patrimonio de cada enclave.

A continuación, se va a exponer un repertorio de lugares-tipo que han demostrado dicha capacidad expresiva, aplicada al caso concreto de la innovación docente en el diseño de Moda. Para generar una clasificación sistemática, se procede a establecer una estructura temática basada en un conjunto de rasgos. A tal fin, se parte de las dos grandes tipologías anteriormente planteadas: adscripciones y participaciones.

\subsection{Adscripciones}

Seguidamente, se relacionan aquellos lugares urbanos que responden a este perfil, correspondientes a la esfera de la Moda, matizando que no ven alterada su naturaleza funcional durante la puesta en práctica de las sinergias. A esta categoría podrían pertenecer aquellos centros y equipamientos con presencia urbana, que la institución docente puede utilizar con el objetivo de enriquecer los procesos formativos de los alumnos y su creatividad. En el caso de la Moda, existe un amplio espectro de lugares que responderían a este perfil; entre otros los siguientes:

- Museos. Con singular relevancia, han de subrayarse aquellos dedicados al Traje, la Antropología, Culturas primitivas, Bellas Artes o a la Moda, en general. En dichos establecimientos, los estudiantes (previa orientación de sus docentes), acceden a contenidos expositivos que refuerzan su formación, fomentando el aprendizaje transversal desde otras áreas de conocimiento.

- Centros de celebración de pasarelas profesionales. Tal sería el caso de recintos feriales, entornos patrimoniales, equipamientos deportivos, edificios religiosos, instalaciones industriales (normalmente rehabilitadas), estaciones de ferrocarril, museos, o fundaciones.

ACE, 15 (4.5) CC BY-ND 3.0 ES | UPC Barcelona, España | La ciudad como escenario de innovación docente. El caso de la pasarela urbana en las enseñanzas de Moda. DOI: http://dx.doi.org/10.5821/ace.15.45.9486 
- Establecimientos industriales. En esta categoría se hallarían los talleres de confección textil, en sus diversas modalidades.

- Equipamientos docentes. Abarcarían edificios de otras instituciones docentes o investigadoras, diferentes de la titular.

- Piezas patrimoniales. Estarían incluidas obras arquitectónicas, sectores urbanísticos o piezas monumentales de cuya experiencia los alumnos pudieran extraer estímulos de diseño.

- Centros y clubes de ocio. Pueden citarse las actividades o espectáculos de perfil lúdico vinculados a la Moda.

- Establecimientos comerciales. En esta categoría se encuadrarían las tiendas de Moda, "concept stores" u otras similares, en cuya visita los estudiantes descubran referentes formativos.

Finalmente, cabe señalar que todos estos lugares de sinergia funcional adscrita se ubican casi exclusivamente en las áreas centrales de las ciudades, salvo los establecimientos industriales, normalmente relegados a zonas periféricas.

\subsection{Participaciones}

Dentro de esta tipología, se va a reflejar un conjunto de lugares urbanos que son de utilidad en la Moda, los cuales ven alterada su naturaleza funcional durante el desarrollo de las sinergias:

a) La primera categoría correspondería a lugares que acogen acciones formativas donde cobran protagonismo los profesionales de la Moda ajenos a las instituciones universitarias, pero susceptibles de despertar creatividad en los alumnos. Tal es el caso de talleres de diseñadores, tiendas y comercios vinculados a este sector. Esta modalidad implica la participación directa de dichos profesionales externos, quienes imparten contenidos docentes "in situ", lo que implica para el alumno un refuerzo en su motivación. En la mayoría de las circunstancias, están insertos en las áreas urbanas centrales, y normalmente en enclaves de un elevado nivel económico y social, a lo que se añade que habitualmente se hallan próximos a piezas patrimoniales de interés. Con frecuencia, se presentan agrupados (en calles o barrios), con la consiguiente contribución a la creación de una seña de identidad vinculada a la Moda en un sector concreto de la metrópoli.

b) La segunda categoría correspondería a aquellos lugares donde se lleva a cabo la exposición de resultados del aprendizaje. Se trata esencialmente de las "pasarelas urbanas", las cuales constituyen un formato pedagógico, expositivo y creativo de creciente impacto, por lo que en el presente bloque temático van a estudiarse detenidamente.

La innovación en las enseñanzas de Moda radica en que, recogiendo la tradición de la presencia urbana de las pasarelas de diseñadores (asunto que se ha tratado en epígrafes precedentes), son los alumnos quienes han accedido a este formato de exposición y proyección socio-urbana. De esta forma, se funde la reciente tradición con la innovación didáctica. En esta importante tipología se añade además el interés patrimonial de que se trate, lo que enriquece el hecho docente en sí mismo, fomenta la creatividad e incrementa la visibilidad y expresividad de los resultados formativos de los estudiantes. A continuación, se analizan diez casos, extraídos del escenario internacional, por considerar que ilustran adecuadamente esta tipología. A tal fin, la estructura de características adopta una estructura similar, para que sea factible establecer lecturas comparadas entre ellos, e incluso extrapolar esta metodología a futuras experiencias.

\section{- Pasarela urbana en Greenwich Village (Nueva York, NY, EE. UU.)}

- Institución o entidad promotora: Parsons The New School for Design (The New School).

- Modelo de implantación urbanística: The New School es una institución de Educación Superior que posee una estructura policéntrica de sedes, mayoritariamente distribuidas por la trama urbana del Bajo Manhattan, en el ámbito del Greenwich Village. Como parte de la institución, la

ACE, 15 (4.5) CC BY-ND 3.0 ES | UPC Barcelona, España | La ciudad como escenario de innovación docente. El caso de la pasarela urbana en las enseñanzas de Moda. DOI: $\underline{\text { http://dx.doi.org/10.5821/ace.15.45.9486 }}$ 
Parsons School of Design tiene su domicilio central en la calle 13, que fue el núcleo espacial en torno al cual se organizó la pasarela urbana.

- Fecha de celebración de la pasarela urbana: 18 de mayo de 2019.

- Actores en el proceso de Enseñanza/Aprendizaje: alumnos graduados en el Degree in Fashion, Design \& Society, docentes y equipo de dirección de Parsons.

- Perfil urbanístico-arquitectónico del escenario: calzadas de los viales urbanos del Bajo Manhattan, cuyo ámbito principal fue la calle 13, entre la 5a Avenida y University Place.

- Escala espacial: realización en enclaves abiertos, a escala urbana, con proyección física y visual sobre las áreas adyacentes.

- Valor patrimonial: bajo un prisma histórico, el sector de Greenwich Village halla sus orígenes a inicios del siglo XVIII, cobrando realce en 1822, cuando recibió una considerable afluencia de población debido a una fiebre amarilla que se sufrió en zonas aledañas. Urbanísticamente, su traza se inserta en la estructura general de Manhattan, cuyo Plan de los Comisionados de 1811 respetó el núcleo histórico del village.

- Rasgos espaciales de la pasarela: el recorrido se superpuso a la retícula ortogonal de los viales de este sector de Manhattan, realizándose a cielo abierto.

- Sinergias con la ciudad: la pasarela se desarrolló en un circuito sobre la calzada situada entre tres vías urbanas del Greenwich Village de Manhattan: 13th Street, Fifth Avenue y University Place (Figura 1). Al finalizar el evento, se procedió igualmente a la apertura de los espacios interiores del edificio del New School's University Center (denominado Parsons East, situado en 25 East, 13th Street). La razón de dicha apertura fue el poder mostrar al público general con mayor grado de detalle las características de los diseños de los alumnos.

- Engarce patrimonio urbano-innovación docente en Moda: el perfil sociourbano del Village es un contexto idóneo para albergar expresiones de la creatividad, como es el caso de una pasarela de Moda, pues se ha caracterizado durante décadas por la cultura alternativa y la vida bohemia, siendo un semillero de movimientos de vanguardia (Banes, 1993). El Village es para los alumnos todo un referente inspirador, capaz de generar ideas de diseño futuras que emanen de la naturaleza vivencial y artística del entorno urbanístico y arquitectónico como factor que despierta modos de sentir y componer.

Figura 1. Pasarela urbana en Greenwich Village, Nueva York, NY (EE.UU.)

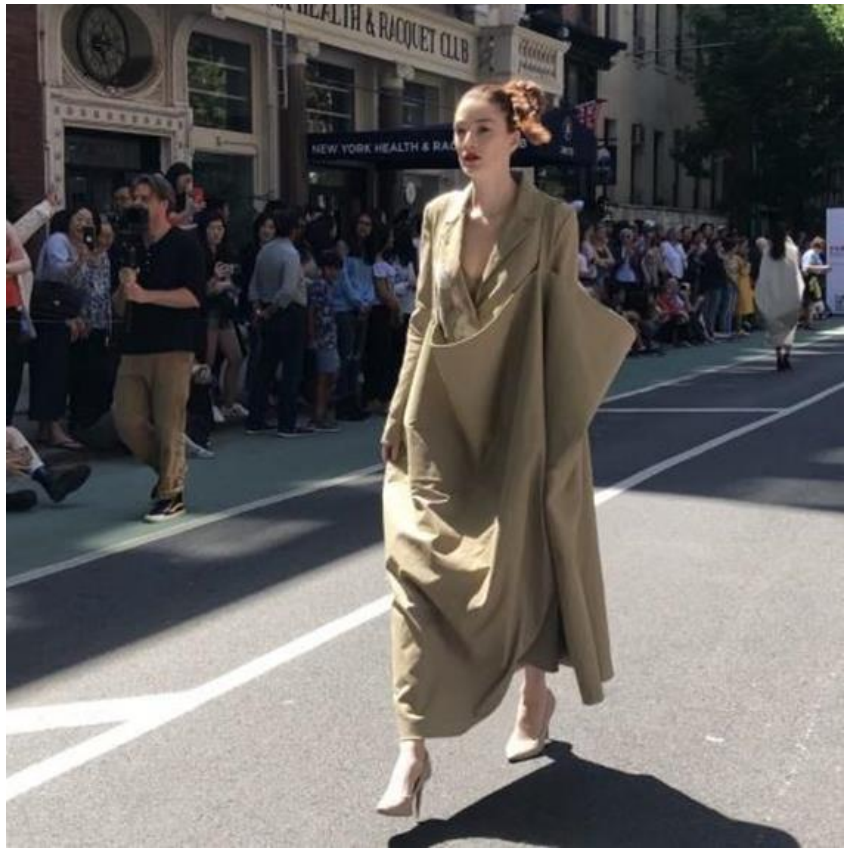

Fuente: Cortesía de The New School.

ACE, 15 (4.5) CC BY-ND 3.0 ES | UPC Barcelona, España | La ciudad como escenario de innovación docente. El caso de la pasarela urbana en las enseñanzas de Moda. DOI: http://dx.doi.org/10.5821/ace.15.45.9486 


\section{- Pasarela urbana en Eilandje (Amberes, Bélgica)}

- Institución o entidad promotora: Académie Royale des Beaux-Arts (AP-University of Applied Sciences and Arts Antwerp).

- Modelo de implantación urbanística: como parte de la estructura general de la AP, los recintos de la Académie Royale des Beaux-Arts se hallan distribuidos por el tejido urbano histórico de Amberes. La sede dedicada a la Moda está situada en el área urbana central (Campus de Coquilhatstraat).

- Fecha de celebración de la pasarela urbana: 1 y 2 de junio de 2018.

- Actores en el proceso de Enseñanza/Aprendizaje: alumnos de los cursos 10 a 4으, del Bachelor y Master of Fine Arts-Costume Design and Fashion.

- Perfil urbanístico-arquitectónico del escenario: complejo arquitectónico exento, asociado a un parque urbano (Park Spoor Nord) situado en el barrio de Eilandje, en el sector noroccidental de Amberes (en adyacencia al río Escalda).

- Escala espacial: realización dentro de un conjunto arquitectónico de antigua función ferroviaria (Parksloods, en el ámbito del Park Spoor Noord), pero con proyección visual sobre un contexto de escala urbanística.

- Valor patrimonial: El conjunto arquitectónico que alberga las pasarelas urbanas fue antiguamente un complejo de hangares ferroviarios. Se rehabilitó en 2011 por la firma Verdickt Architects, proyecto que consiguió el Premio EU-Mies-Award.

- Rasgos espaciales de la pasarela: ubicación interior, de pauta lineal, adaptada al patrón compositivo de los antiguos hangares, a base de una retícula ortogonal.

- Sinergias con la ciudad: el núcleo espacial del desfile (Parksloods) se abre a un espacio libre (Park Spoor Nord), que representa la recualificación sociourbana de este sector. Se halla cerca del barrio Eilandje, que a su vez ha experimentado una sensible transformación cualitativa (Merckx, Noteboom, y Winkelmans, 2003). Ha pasado de ser una zona portuaria a otra bohemia y de creatividad, con la presencia de destacados museos, como el Museum Aan De Stroom (diseñado por Neutelings), y el Red Star Line Museum, así como obras deconstructivistas, como el Havenhuis (Casa del Puerto), que ideó Zaha Hadid. Las pasarelas urbanas adquieren una notable proyección social, con una gran capacidad de convocatoria, pues asisten más de 4.000 personas.

- Engarce patrimonio urbano-innovación docente en Moda: La ciudad de Amberes ha experimentado desde hace años el impulso creativo de la Moda (Pappacoda, 1987). Como derivada de lo anterior, el emergente complejo de Eilandje actúa como catalizador de una renovación urbana en este sector, anteriormente deprimido (donde surgió el citado Park Spoor Nord). Por ello, emplearlo como escenario de desfiles de Moda trae como consecuencia una extraordinaria sinergia: superponer la creatividad inherente a esta disciplina del diseño con la propia de la transformación urbanística y social del contexto patrimonial.

- Pasarela urbana en el Teatro Real (Madrid, España)

- Institución o entidad promotora: Centro Superior de Diseño de Moda de Madrid-CSDMM (Universidad Politécnica de Madrid).

- Modelo de implantación urbanística: la sede central de esta institución se halla en el Campus Sur de la Universidad Politécnica de Madrid, dentro del distrito del Puente de Vallecas. La UPM posee una estructura policéntrica en torno a la metrópoli, hallándose su núcleo principal en la Ciudad Universitaria.

- Fecha de celebración de la pasarela urbana: 21 de junio de 2016.

- Actores en el proceso de Enseñanza/Aprendizaje: alumnos de 4o curso del Grado en Diseño de Moda, profesores y equipo directivo del CSDMM. 
- Perfil urbanístico-arquitectónico del escenario: pieza arquitectónica exenta, situada en el área urbana central de Madrid (Distrito Centro-Plaza de Oriente).

- Escala espacial: realización dentro de una pieza arquitectónica, pero con proyección visual sobre un contexto urbanístico.

- Valor patrimonial: obra trazada a partir de 1818 por Antonio López Aguado, Francisco Cabezuelo y Custodio Teodoro Moreno (Navascués, 1971). Tras sucesivas reformas llevadas a cabo durante décadas, su estado final fue proyectado en 1993 por Rodríguez de Partearroyo. Actualmente, el edificio propone una renovada expresión arquitectónica que procura activar un diálogo entre la herencia estilística original y un lenguaje con identidad moderna.

- Rasgos espaciales de la pasarela: ubicación elevada, transitando por espacios internos y terrazas exteriores de la planta primera, con desarrollo en forma semi-trapezoidal en planta.

- Sinergias con la ciudad: el ámbito de la pasarela estuvo abierto a un espacio libre urbano de alta valía histórica y patrimonial (la Plaza de Oriente), desde donde era visible por parte del público general (Figura 2). La celebración del desfile en semejante contexto implicó la participación, como escenario de interacción artística, del complejo formado por diversos elementos: la propia pieza monumental del Teatro Real, así como el entorno urbano inmediato, donde se sitúan los jardines de la Plaza de Oriente y el Palacio Real.

- Engarce patrimonio urbano-innovación docente en Moda: la pasarela se ubicó en un contexto de gran significación urbanístico-arquitectónica, que ha experimentado diversos procesos de renovación a lo largo de la historia. De este modo, la exposición de diseños de los alumnos generó una superposición de creatividades: por un lado, la innovación inherente al formato espacial del desfile; por otro, la inercia de recualificación que ha caracterizado a las sucesivas transformaciones del entorno del Teatro Real y su enclave histórico.

Figura 2. Pasarela urbana en el Teatro Real, Madrid (España)

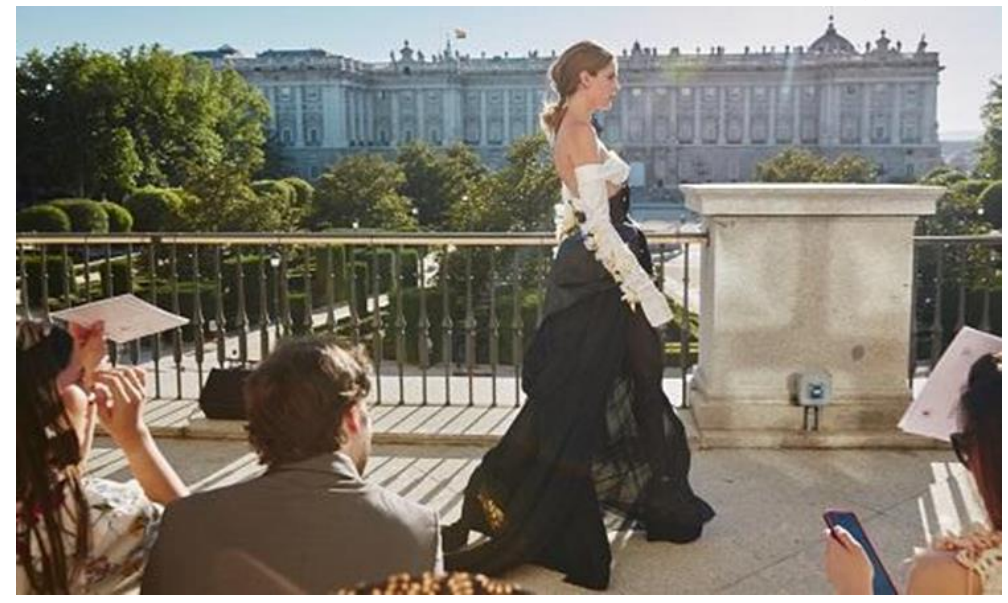

Fuente: Cortesía del CSDMM

- Pasarela urbana en el Museo de Arte (Savannah, GA, EE. UU.)

- Institución o entidad promotora: Savannah College of Art and Design (SCAD).

- Modelo de implantación urbanística: La institución tiene varias sedes, en Atlanta y Savannah (Estado de Georgia). En ambas, se organiza en forma de estructura policéntrica. En Savannah, la institución docente establece sinergias son un conjunto de equipamientos sociales y culturales, distribuidos a lo largo de la retícula ortogonal de la ciudad; uno de ellos es el Museo de Arte.

- Fecha de celebración de la pasarela urbana: 17 de mayo de 2014.

- Actores en el proceso de Enseñanza/Aprendizaje: alumnos graduados en el Bachelor Fine Arts, Master of Arts y Master of Fine Arts.

ACE, 15 (4.5) CC BY-ND 3.0 ES | UPC Barcelona, España | La ciudad como escenario de innovación docente. El caso de la pasarela urbana en las enseñanzas de Moda. DOI: http://dx.doi.org/10.5821/ace.15.45.9486 
- Perfil urbanístico-arquitectónico del escenario: pieza arquitectónica exenta, el Museo de Arte, localizado en el sector noroccidental de la metrópoli de Savannah.

- Escala espacial: realización en el interior de una pieza arquitectónica, situada en un ámbito urbano en el que se hallan otros equipamientos museísticos (Savannah History Museum, Georgia State Museum, o Ralph Gilbert Civil Rights Museum).

- Valor patrimonial: el Museo de Arte fue construido en 1853, como instalación al servicio del Central for Georgia Railway. Se trata de una estructura de estilo neogriego, que emplea el ladrillo como material predominante, y que fue declarada Monumento Histórico Nacional. Las sucesivas operaciones de reforma y adecuación finalizaron en 2011, bajo diseño de la firma local Sottile \& Sottile.

- Rasgos espaciales de la pasarela: ubicación en el interior del edificio, ajustando el itinerario de exhibición a los espacios preexistentes, tributarios de una retícula ortogonal con predominio de la linealidad, ajustada al vial adyacente (Turner Boulevard).

- Sinergias con la ciudad: el Museo de Arte sirve tanto a la institución académica (SCAD), como al entorno social de Savannah y a visitantes externos, erigiéndose en un enclave cultural que fomenta las sinergias entre ciudad e institución docente (Figura 3). Como muestra añadida de ello, cabe apuntar que el SCAD impulsó el proceso de rehabilitación del edificio, como muestra de su compromiso para con los estudiantes y la comunidad social del entorno.

- Engarce patrimonio urbano-innovación docente en Moda: la pasarela se emplazó en un escenario de considerable peso patrimonial, derivado del valor histórico y arquitectónico de la pieza rehabilitada, y a su contenido artístico, creativo por naturaleza. A ello se suma la política de la institución de fomentar la reforma de antiguas estructuras urbanístico-arquitectónicas en Savannah (Pinkelton, y Burke, 2004). Dicho escenario general, caracterizado por la innovación como seña de identidad, ofreció un marco idóneo para superponer sobre él otra realidad creativa, como lo es el desfile donde se expresan en público los diseños de Moda.

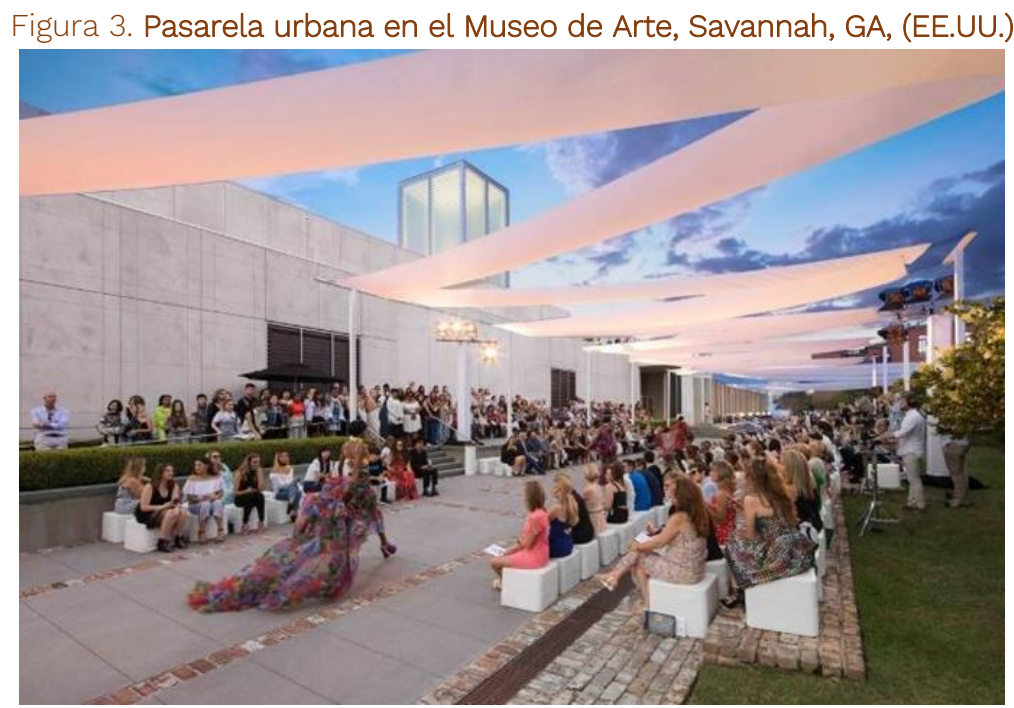

Fuente: cortesía del SCAD

\section{- Pasarela urbana en el Centro Cultural Conde Duque (Madrid, España)}

- Institución o entidad promotora: Centro Superior de Diseño de Moda de Madrid-CSDMM (Universidad Politécnica de Madrid).

- Modelo de implantación urbanística: ya reseñado anteriormente.

- Fecha de celebración de la pasarela urbana: 20 de septiembre de 2017.

ACE, 15 (4.5) CC BY-ND 3.0 ES | UPC Barcelona, España | La ciudad como escenario de innovación docente. El caso de la pasarela urbana en las enseñanzas de Moda. DOI: http://dx.doi.org/10.5821/ace.15.45.9486 
- Actores en el proceso de Enseñanza/Aprendizaje: alumnos de 4o curso del Grado en Diseño de Moda, profesores y equipo directivo del CSDMM.

- Perfil urbanístico-arquitectónico del escenario: viales urbanos adyacentes a la pieza arquitectónica exenta del Cuartel del Conde Duque, situado en el área urbana central de Madrid (Distrito Centro).

- Escala espacial: la pasarela se caracterizó por su escala urbanística, si bien también interactuó con la pieza arquitectónica, al enlazar con los ámbitos internos de la misma.

- Valor patrimonial: el proyecto del Cuartel de Conde Duque nació en 1717 como encargo al arquitecto Pedro de Ribera de levantar una estructura cuartelaria, revestida de pautas estilísticas barrocas. Tras diversos avatares, la sólida y racional pieza patrimonial fue transformada en Centro Cultural bajo diseño de Julio Cano Lasso en 1981. Fue declarado Monumento Histórico Artístico en 1976 (Echeverría, 2011).

- Rasgos espaciales de la pasarela: se desarrolló esencialmente siguiendo una pauta lineal, sobre el vial urbano anexo a la pieza arquitectónica (Calle del Conde Duque).

- Sinergias con la ciudad: la pasarela urbana generó una sinergia física directa con el sector urbano adyacente, la Calle del Conde Duque, de recorrido tangente a la fachada lineal de la pieza arquitectónica, y asimismo respecto a espacios libres de escala menor, como la anexa plaza de Guardias de Corps (Figura 4). La gran portada barroca, ejecutada en piedra, fue empleada como elemento de ingreso y salida de las modelos, para acceder directamente al vial adyacente, en un recorrido lineal paralelo al monumental paramento de ladrillo.

- Engarce patrimonio urbano-innovación docente en Moda: la pasarela se alojó en un entorno patrimonial de elevada significación. La proyección física sobre las zonas urbanas anexas aportó un valor añadido, como manifestación de la vocación de la Moda de salir al encuentro con la realidad social. Como factor creativo heredado, se sumó la propia renovación del edificio, que transformó su antigua función militar en otra cultural. Todos estos ingredientes urbanísticoarquitectónicos definieron un trasfondo idóneo para exhibir la creatividad de los diseños de los alumnos, asumiéndolos como expresiones de análoga renovación.

Figura 4. Pasarela urbana en Conde Duque, Madrid (España)

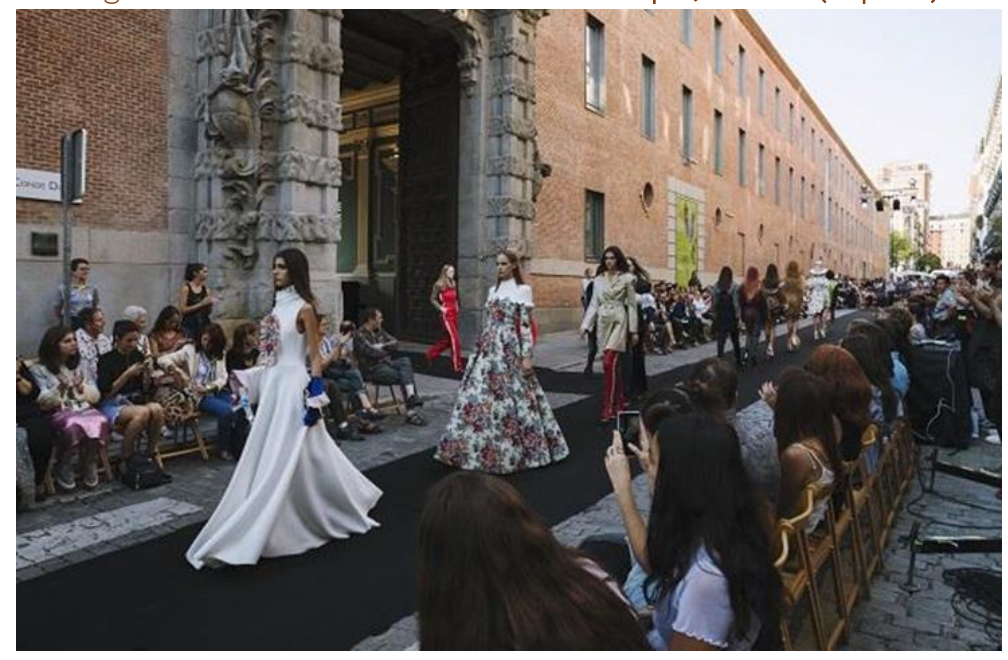

Fuente: Cortesía del CSDMM

- Pasarela urbana en el Teatro Vetra (Milán, Italia)

- Institución o entidad promotora: Istituto Marangoni.

- Modelo de implantación urbanística: la entidad posee varias sedes de Moda en ciudades como Florencia, París, Londres, Bombai y Miami. En Milán, se ubica en la Via Pietro Vetri, dentro del centro histórico de la ciudad.

ACE, 15 (4.5) CC BY-ND 3.0 ES | UPC Barcelona, España | La ciudad como escenario de innovación docente. El caso 13 de la pasarela urbana en las enseñanzas de Moda. DOI: http://dx.doi.org/10.5821/ace.15.45.9486 
- Fecha de celebración de la pasarela urbana: 20 de junio de 2017.

- Actores en el proceso de Enseñanza/Aprendizaje: 10 alumnos graduados en la Milano School of Fashion del Istituto Marangoni, y equipo directivo de la entidad.

- Perfil urbanístico-arquitectónico del escenario: pieza arquitectónica exenta (Teatro Vetra), situada en el área urbana central de Milán.

- Escala espacial: desarrollo dentro de una pieza arquitectónica, pero con proyección sobre un contexto de escala urbana.

- Valor patrimonial: el estado actual del edificio es el resultado de un proceso de transformación funcional y arquitectónico, pues con anterioridad había albergado una sala teatral, denominada Alcione (erigida en 1928 con diseño de Alfredo Campanini, tributario del estilo Art Nouveau-Liberty), y más tarde, como sala de teatro Excelsior. En 2006, la estructura fue rehabilitada, según proyecto de Rocco Magnoli, y bajo el impulso promotor de Versace. A su entidad patrimonial se suma el hecho de que se enclava en la Piaza Vetra, cuya relevancia se acentúa por la presencia de edificios históricos.

- Rasgos espaciales de la pasarela: ubicación interior, dentro de la gran sala de planta ovalada del Teatro Vetra.

- Sinergias con la ciudad: el Teatro Vetra se halla enclavado en una de las áreas más vibrantes y multifuncionales de Milán. La propia sala porta en su trayectoria una seña de identidad impregnada de la vanguardia inherente a la Moda. La sinergia física con el entorno metropolitano se beneficia asimismo de la presencia inmediata de la Piazza Vetra, donde se levanta la Basílica de San Lorenzo Maggiore.

- Engarce patrimonio urbano-innovación docente en Moda: el Teatro Vetra posee un notable interés estilístico (heredero del Art Nouveau) que, tras su cierre, experimentó un resurgimiento impulsado desde la esfera de la Moda, al transformarse en 2006 en Teatro Versace. La celebración de la pasarela del Istituto Marangoni implicó una cierta superposición de creatividades entre Moda y Arquitectura, pues la pieza pasó a ser en sí misma representativa de la vanguardia en el campo de los modistos.

- Pasarela urbana en Rue Antibes, y Palacio de Festivales (Cannes, Francia)

- Institución o entidad promotora: École de Mode Cours Aline Buffet.

- Modelo de implantación urbanística: la entidad se halla situada en el centro histórico de la ciudad de Cannes, en la Rue d'Alger.

- Fechas de celebración de la pasarela urbana: 11 y 12 de enero de 2020.

- Actores en el proceso de Enseñanza/Aprendizaje: alumnos graduados en la École de Mode Cours Aline Buffet, y directora de la institución docente.

- Perfil urbanístico-arquitectónico del escenario: calzada de la vía urbana (Rue d'Antibes) del centro histórico de Cannes, cercano al núcleo ciudadano donde se levanta el Palais des Festivals et des Congrés, que albergó la primera sesión de la pasarela.

- Escala espacial: se desarrolló en dos fases, una a escala de pieza arquitectónica y otra en espacios abiertos a escala urbana, con proyección física y visual sobre las áreas anexas.

- Valor patrimonial: en una somera revisión histórica, el sector metropolitano que acogió a ambos desfiles es el centro histórico de la ciudad, que se abre al frente marino. La ubicación del Palacio de Festivales, erigido sobre el emplazamiento del antiguo Casino municipal, es próxima a la Rue d'Antibes (cuyo recorrido coincide con la antigua carretera que conducía a Antibes, y que fue gradualmente urbanizada a partir del siglo XVIII), estando ambos en la zona metropolitana que experimentó un desarrollo significativo a lo largo del siglo XIX.

- Rasgos espaciales de la pasarela: el recorrido se superpuso a la trama curvilínea de la Rue d'Antibes, realizándose a cielo abierto. Complementariamente, la víspera se había realizado dentro del auditorio del Palacio de Festivales.

ACE, 15 (4.5) CC BY-ND 3.0 ES | UPC Barcelona, España | La ciudad como escenario de innovación docente. El caso de la pasarela urbana en las enseñanzas de Moda. DOI: http://dx.doi.org/10.5821/ace.15.45.9486 
- Sinergias con la ciudad: la pasarela combinó dos formatos convergentes. Por un lado, dentro del Palacio, lo que supuso una superposición espacial que aprovechó la inercia histórica del Festival de Cine, cuyo impacto social y urbanístico es muy considerable (Ostrowska, 2017). Por otro, la sinergia con la ciudad se tradujo a una acción muy expresiva: invadir el tejido urbano. Ello se logró al desplegarse sobre una calle de gran atractivo y dinamismo: la Rue d'Antibes, situada a escasa distancia del Palacio, involucrando también a la Galería Gray D’ Albion.

- Engarce patrimonio urbano-innovación docente en Moda: el Palacio de Cannes es un edificio diseñado en 1979 por Bennett \& Druet (el cual reemplaza al histórico, erigido en 1949), donde se celebra el Festival de Cine. Esta pieza aportó un valor añadido a la pasarela de Moda, por cuanto a la creatividad Moda-Arquitectura se sumó la inherente al Arte cinematográfico. Simultáneamente, la celebración al día siguiente de la pasarela en la Rue d’Antibes implicó dotar al desfile de otra dimensión innovadora añadida, al proyectarse directamente sobre el entorno ciudadano. Ello refleja la pretensión de Aline Buffet de transmitir directa y expresivamente el universo de la Moda a las nuevas generaciones.

\section{- Pasarela urbana en el Teatre Alegria (Terrassa, España)}

- Institución o entidad promotora: Escuela de Moda Felicidad Duce LCI Barcelona

- Modelo de implantación urbanística: la sede central de esta institución se halla en el centro de Barcelona (c/Balmes). La red internacional LCl Education posee diversas implantaciones en 23 localizaciones internacionales; en Barcelona, cuenta con 7 Escuelas, que comparten espacio en el barrio de Sant Gervasi.

- Fecha de celebración de la pasarela urbana: 8 de marzo de 2018.

- Actores en el proceso de Enseñanza/Aprendizaje: alumnos de 3o y 4o curso de la asignatura de Proyectos de Estilismo/Creatividad y de la optativa de Creatividad, y equipo directivo de la Escuela de Moda Felicidad Duce LCI Barcelona.

- Perfil urbanístico-arquitectónico del escenario: pieza arquitectónica exenta, situada en el área urbana central de Terrassa (Calle Gaudí, 15).

- Escala espacial: realización dentro de una pieza arquitectónica, integrada en un complejo de mayor entidad (el Institut del Teatre), pero con proyección sobre un contexto urbanístico de alta significación.

- Valor patrimonial: Terrassa es ciudad legataria de la industria, muchos de cuyos equipamientos históricos tributaron al movimiento modernista (Mas y Sabaté, 2013). El Teatre Alegria forma parte de un conjunto arquitectónico de considerable valor, inserto en el sector histórico de la urbe. Se trata del antiguo Vapor Mata, una pieza de la industria textil, trazada en 1921 por el arquitecto modernista Lluis Muncunill, que fue transformado recientemente, con aportaciones de Joan Jorba y Francesc Bacardit. En su estado actual, el edificio propone una renovada expresión arquitectónica, que trata de combinar memoria y vanguardia.

- Rasgos espaciales de la pasarela: ubicación interior al Teatre Alegria, desplegada por sus ámbitos centrales siguiendo una pauta compositiva lineal en planta.

- Sinergias con la ciudad: en el entorno patrimonial se hallaban equipamientos tan relevantes como el Institut del Teatre, la Catedral (en la Plaça Vella), el Ayuntamiento, el Museo de la Ciencia y de la Técnica (también diseñado por Muncunill), y espacios libres como el Parc de Vallparadís (declarado en 1951 Monumento Histórico Artístico), al que se asoma el conjunto patrimonial de la Seu d'Egara. La pasarela urbana encajaba en un contexto propicio para las sinergias, al compartir la vocación por la creatividad en el siglo XXI, pues Terrasa apuesta por la fusión entre ciudad, cultura y comercio, compaginando su tradición textil con la innovación.

ACE, 15 (4.5) CC BY-ND 3.0 ES | UPC Barcelona, España | La ciudad como escenario de innovación docente. El caso 15 de la pasarela urbana en las enseñanzas de Moda. DOI: $\underline{\text { http://dx.doi.org/10.5821/ace.15.45.9486 }}$ 
- Engarce patrimonio urbano-innovación docente en Moda: La pasarela, denominada XII Desfilada de la Creativitat, se desarrolló en un entorno caracterizado por la innovación, en diversos planos. La propia de exponer resultados docentes en un lugar distinto a la sede habitual de LCI Barcelona, se solapó con la inercia creativa de la ciudad, que ha sabido transformar su herencia industrial en un potente patrimonio moderno, que reafirma la identidad colectiva. Un componente esencial de dicha herencia fue el sector textil, lo que redunda en la coherencia de elegir este centro histórico como escenario de una pasarela de Moda, donde los estudiantes se sumaron al espíritu de realce de la identidad ciudadana. El evento añadió otro aspecto docente innovador: la transversalidad, al colaborar estudiantes de la Escuela ESTAE del Institut del Teatre y del Institut d'Estudis Fotogràfics de Catalunya.

\section{- Pasarela urbana en DIMAD (Madrid, España)}

- Institución o entidad promotora: Centro Superior de Diseño de Moda de Madrid (Universidad Politécnica de Madrid).

- Modelo de implantación urbanística: ya reseñado anteriormente.

- Fecha de celebración de la pasarela urbana: 4 de junio de 2019.

- Actores en el proceso de Enseñanza/Aprendizaje: alumnos de 1o curso del Grado en Diseño de Moda, profesores y equipo directivo del CSDMM.

- Perfil urbanístico-arquitectónico del escenario: pieza arquitectónica exenta (la nave que alberga DIMAD-Central de Diseño de Madrid), encuadrada en el complejo Matadero-Madrid, situado en el sector sudoriental del área urbana (Distrito Arganzuela), junto al río Manzanares.

- Escala espacial: realización dentro de una pieza arquitectónica, pero con proyección espacial sobre el complejo de Matadero-Madrid y el contexto urbanístico adyacente.

- Valor patrimonial: la nave de DIMAD pertenece al conjunto originalmente denominado Matadero y Mercado Municipal de Ganados. El proyecto, diseñado por Bellido y Ribera en 1908 con influencias del estilo neomudéjar, cesó sus actividades en 1996, y en 2007 fue reconvertido en un innovador espacio cultural de la ciudad, dinamizando así la recualificación integral del barrio de la Chopera. En el largo proceso de reforma, intervinieron diversos arquitectos, entre los cuales cabe destacar a Fernández Alba. Se trata de un extraordinario ejemplo de metamorfosis urbanística, funcional y arquitectónica en la ciudad, con una marcada impronta cultural (González, 2019).

- Rasgos espaciales de la pasarela: ubicación interior, desarrollándose en forma cuadrada en planta, ubicándose los asientos para el público en el centro y en los laterales.

- Sinergias con la ciudad: los ámbitos construidos del propio complejo de Matadero-Madrid fueron un ámbito de proyección de la actividad de innovación docente. También lo fue el entorno urbano, respecto al cual el conjunto se alinea a lo largo del Paseo de la Chopera, en proximidad a otra gran intervención urbana, Madrid-Río. La pasarela de estudiantes de Moda se sumó a las sinergias de gran entidad promovidas por la totalidad del Espacio Cultural (Figura 5), cuya presencia ha dinamizado este sector de Madrid en los últimos años.

- Engarce patrimonio urbano-innovación docente en Moda: emplazamiento en un contexto patrimonial de gran significación urbanístico-arquitectónica, al haber mutado de su pasada función industrial a otra de creatividad cultural. La exposición de las colecciones de los alumnos se llevó a cabo en un ámbito general (Matadero-Madrid) caracterizado por la transversalidad entre disciplinas artísticas. El lema del evento ("Paintfull”) hacía un guiño a la conexión entre la Moda y otro tipo de expresiones estéticas.

ACE, 15 (4.5) CC BY-ND 3.0 ES | UPC Barcelona, España | La ciudad como escenario de innovación docente. El caso 16 de la pasarela urbana en las enseñanzas de Moda. DOI: http://dx.doi.org/10.5821/ace.15.45.9486 
Figura 5. Pasarela urbana en DIMAD, Madrid (España)

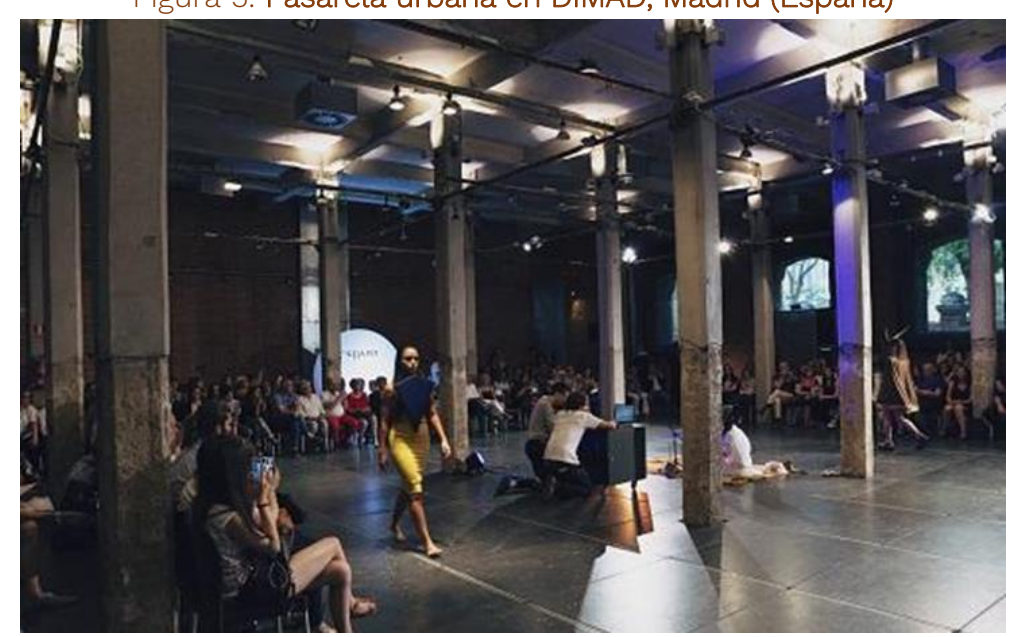

Fuente: Cortesía del CSDMM

- Pasarela urbana en la Via Tornabuoni (Florencia, Italia)

- Institución o entidad promotora: Istituto Marangoni.

- Modelo de implantación urbanística: como se ha señalado anteriormente, esta entidad posee sedes de Moda en ciudades como Milán, París, Londres, Bombai y Miami. En Florencia, se emplaza en la Via Tornabuni, inserta en el tejido histórico de la urbe.

- Fecha de celebración de la pasarela urbana: 10 de junio de 2019.

- Actores en el proceso de Enseñanza/Aprendizaje: alumnos del 3o curso del Programa en Fashion Design del Istituto Marangoni.

- Perfil urbanístico-arquitectónico del escenario: vial urbano (Via Tornabuoni), situada en el área central de Florencia, donde la entidad tiene su sede (el Palazzeto Tornabuoni, que data del siglo

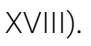

- Escala espacial: el desarrollo de la pasarela se produjo a escala urbana, si bien con cierta influencia de la escala arquitectónica, pues el desfile se inició y finalizó en la sede del Istituto Marangoni, que está en el mismo vial donde se celebró el evento.

- Valor patrimonial: la Via Tornabuoni es una de las arterias de mayor significación histórica y patrimonial en la ciudad de Florencia (Luigi, 1995). Su configuración actual surgió en el Renacimiento, cuando experimentó una transformación que trajo consigo la construcción de numerosos palacios, que aportaron una potente seña de identidad patrimonial.

- Rasgos espaciales de la pasarela: emplazamiento exterior, superpuesto a la calzada de la Via Tornabuoni, disponiendo de una superficie de madera que realzó el recorrido lineal, dentro de un paisaje urbano de fachadas engalanadas para la ocasión.

- Sinergias con la ciudad: el Istituto Marangoni abrió su sede florentina en 2017, para estar presente en una ciudad que aporta un ingente valor patrimonial y cultural, y que posee una sólida trayectoria en Moda. Se ubicó en un antiguo Palazzo dieciochesco, adyacente al Palazzo Larderel y al Palazzo Viviani dell Robbia, y en la inmediatez del Palazzo Strozzi, obra renacentista diseñada por Benedetto da Maiano y concluida en 1534. A su lado se halla el Palacio Tornabuoni (trazado por Michelozzo). En el extremo Sur de la calle se halla el Museo Salvatore Ferragamo. La Via Tornabuoni es un eje impregnado de la seña de identidad que aporta la creatividad en Moda (Capone, y Lazzeretti, 2016). La celebración de la pasarela urbana expresó la voluntad de la entidad de proyectar la Moda al entorno socio-urbano (Figura 6).

- Engarce patrimonio urbano-innovación docente en Moda: la Via Tornabuoni, que sirvió como soporte al desfile, acoge numerosas marcas de prestigio y locales de diseñadores de joyería y

ACE, 15 (4.5) CC BY-ND 3.0 ES | UPC Barcelona, España | La ciudad como escenario de innovación docente. El caso de la pasarela urbana en las enseñanzas de Moda. DOI: http://dx.doi.org/10.5821/ace.15.45.9486 
Moda. Por ello, elegirla emplazamiento para la pasarela urbana organizada por el Istituto Marangoni dio lugar a una positiva redundancia, en clave creativa, puesto que el escenario urbanísticoarquitectónico expresaba en sí mismo el peso histórico y social que la Moda posee en Florencia.

Figura 6. Pasarela urbana en Via Tornabuoni, Florencia (Italia)

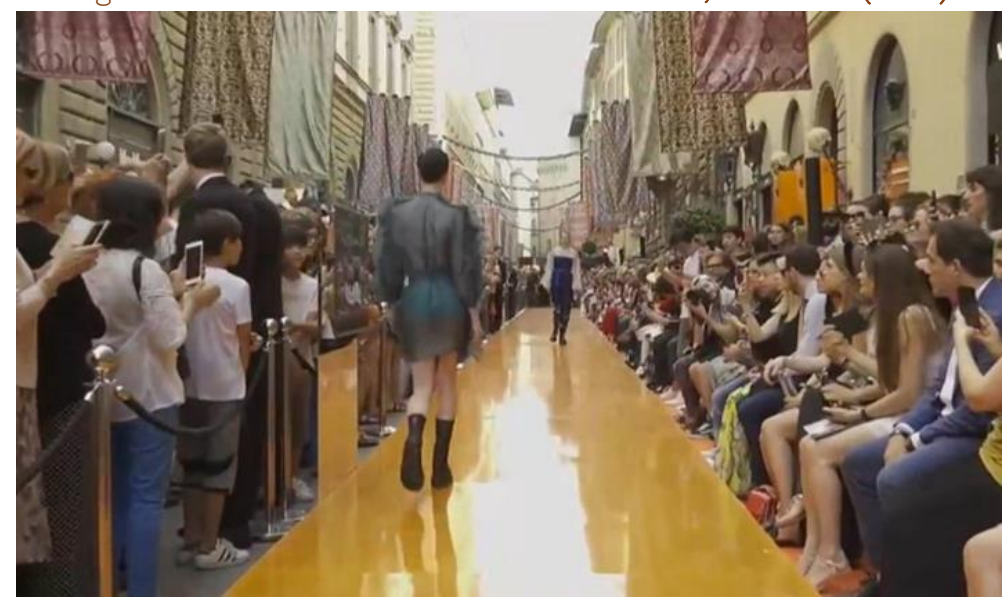

Fuente: Cortesía del Istituto Marangoni.

\section{Resultados, proactividad y conclusiones}

Las misiones de la universidad, complementadas por su dimensión urbanístico-arquitectónica, son toda una energía de transformación, que enriquece a la sociedad. En la coyuntura presente, resulta beneficioso compaginar la innovación docente con el recurso a la ciudad, como suministradora de valores culturales y patrimoniales. Incrementar la visibilidad de cuantas actividades fomentan dichas instituciones en la cotidianeidad ciudadana es, en sí misma, una actitud consustancial a sus misiones, y adquiere todo un potencial proactivo de influencia positiva sobre el panorama educativo general.

Esbozar un elenco de conclusiones ha de venir precedido por una sucinta evocación de la memoria universitario-urbana. Durante siglos, el Saber ha estado vinculado a los núcleos históricos de las ciudades, salvo en las desacertadas dinámicas de abandono de estos que tuvieron lugar en la segunda mitad del siglo XX. Dicha vinculación implicó el disfrute de sinergias recíprocas que, tras el surgimiento del paradigma del campus americano, adquirió nuevos formatos y significados. En las circunstancias actuales, resulta indudable que la participación activa de la ciudad suministra beneficios añadidos a la labor educativa. Proyectándose funcional y espacialmente sobre el tejido urbano, las instituciones docentes salen al encuentro de la sociedad, convirtiendo a los contextos patrimoniales en actores necesarios de cara a la innovación. Como caso singular de importancia, las descritas pasarelas urbanas protagonizadas por estudiantes son un elocuente ejemplo de reciente cuño, erigiéndose en expresión de la referida innovación docente. Uno de los resultados más valiosos de las mismas ha sido el positivo impacto académico en los alumnos del Grado en Moda. En el caso concreto del CSDMM, dicho impacto se tradujo a un incremento en las calificaciones de sus respectivos Trabajos Fin de Grado, en comparación con las de años anteriores. El éxito principal en materia de aprendizaje innovador fue que las pasarelas urbanas incrementaron la motivación estudiantil. En ese sentido, resulta ilustrativo recoger ciertas valoraciones cualitativas. La motivación se vio altamente incrementada, pues a la exposición pública de los diseños (de alto interés para el alumnado), se sumó la interacción con enclaves metropolitanos ajenos a sus lugares de estudio habituales. Dicha motivación se vio por ende aumentada, debido a que las pasarelas se desplegaron sobre entornos patrimoniales de alta significación, lo que añadió un escenario espectacular para acoger en su seno

ACE, 15 (4.5) CC BY-ND 3.0 ES | UPC Barcelona, España | La ciudad como escenario de innovación docente. El caso 18 de la pasarela urbana en las enseñanzas de Moda. DOI: http://dx.doi.org/10.5821/ace.15.45.9486 
los trabajos académicos. Salvo los pocos estudiantes que decidieron no desfilar por falta de tiempo, la gran mayoría participó no sólo con sus diseños, sino directamente en la organización del evento. Para ellos, estos desfiles constituyeron, en efecto, la mayor motivación de cada curso. Como muestra de la alta aceptación de estos eventos, en el celebrado en el Teatro Real participaron 27 alumnos de 4- Curso, los cuales mostraron antes y después del acto, su satisfacción por haberse elegido un escenario patrimonial de alta significación en la ciudad. Similares testimonios fueron expresados por los 16 alumnos que expusieron en la pasarela urbana de Conde Duque, quienes manifestaron su disfrute por el hecho de que el recorrido de las modelos se desplegó a pie de calle, en el marco patrimonial protagonizado por la pieza que diseñara Ribera en el siglo XVIII.

Se ha constatado que las pasarelas urbanas, como experiencias de innovación docente, han constituido también una extraordinaria estrategia de convocatoria a la participación del patrimonio de la ciudad. La activación de sinergias socio-urbanas entre las instituciones de enseñanza en Moda y los enclaves urbanos, observables en los casos analizados, induce dos niveles de creatividad. Por un lado, se solapa la creatividad inherente a la formación de diseñadores con la latente en determinados sectores urbanos, cuya seña de identidad puede ser la vanguardia artística, cultural o patrimonial. Por otro, los diseños de las colecciones elaboradas por los alumnos ven realzada su expresión pública si para ello se elige un contexto arquitectónico o urbanístico de especial significación; como se ha avanzado en epígrafes anteriores, Arquitectura y Moda atesoran engarces compositivos diversos, lo que incrementa la sintonía estética entre ambas. La mera contemplación e interpretación estética de la Arquitectura es una estrategia susceptible de suministrar engarces conceptuales y formales con la Moda, pues ambas disciplinas comparten temas que arman todo un corpus compositivo común, que ya se ha avanzado en epígrafes precedentes: orden, proporción, ritmo, volumen, transparencia, textura o color, entre otros. La imagen de estudiantes mostrando los resultados de sus creaciones en ámbitos ciudadanos constituye todo un manifiesto que reivindica el decisivo rol social que la educación debe ejercer. Expresado, en otros términos, cuando se utilizan escenarios urbanos para albergar pasarelas de alumnos, éstas se ven enriquecidas por el aporte patrimonial del lugar elegido. Ello no solamente construye un marco de valor estético, sino que incrementa la visibilidad de los trabajos de los alumnos. Virtudes todas ellas que se evidencian en los casos analizados: Amberes, Madrid, Savannah, Milán, Cannes, Terrassa, Florencia y Nueva York. Como conclusión de perfil proactivo, las experiencias descritas podrían extrapolarse a otras ciudades diferentes, pues los fundamentos son de plena aplicación universal. Como beneficio complementario, dichos escenarios patrimoniales atesoran una cualidad añadida, como es la de inducir creatividades futuras. Y también podrían aplicarse en otro tipo de disciplinas, como la enseñanza de la propia Arquitectura, entre otras posibles.

Cabe concluir con otra reflexión de corte proactivo. A la vista de las experiencias que ya se despliegan en el escenario internacional (concretamente ilustradas con el caso de las pasarelas docentes en Moda), activar sinergias con la ciudad es una dinámica susceptible de aportar valor añadido al proceso formativo de los alumnos universitarios, en general. Idear estrategias de innovación que aprovechen sus valores patrimoniales es una actitud llamada a generar beneficios recíprocos. La ciudad es en sí misma, todo un recurso formativo.

\section{Agradecimientos}

Los autores quieren expresar su agradecimiento a los revisores del artículo, así como al Centro Superior de Diseño de moda de Madrid - Universidad Politécnica de Madrid y a la Universidad CEU San Pablo.

ACE, 15 (4.5) CC BY-ND 3.0 ES | UPC Barcelona, España | La ciudad como escenario de innovación docente. El caso de la pasarela urbana en las enseñanzas de Moda. DOI: http://dx.doi.org/10.5821/ace.15.45.9486 


\section{Autoría}

La primera autora ha investigado los temas relacionados con la moda y la pasarela docente y el segundo autor ha analizado la vertiente urbanística y arquitectónica de estos eventos.

Conflicto de intereses: Los autores declaran que no hay conflicto de intereses.

\section{Bibliografía}

Aranguren, C. (2003). La Ciudad en el Aula: Algunas Propuestas Teórico-Didácticas para su Enseñanza. Acción Pedagógica, 12(1), 80-84. Recuperado de https://dialnet.unirioja.es/servlet/articulo?codigo $=2972879$

Asociación Mundial de Ciudades Educadoras (1990). Carta de ciudades educadoras. Barcelona, España: Edcities. Recuperado de https://www.edcities.org/wp-content/uploads/2013/10/CARTACIUDADES-EDUCADORAS 3idiomas.pdf

Banes, S. (1993). Greenwich Village 1963: avant-garde performance and the effervescent body. Durnham, NC, EE. UU.: Duke University Press.

Bellet, C. y Ganau, J. (eds.) (2006). Ciudad y universidad: ciudades universitarias y campus urbanos. Lleida, España: Milenio.

Benjamin, W. (2005). Passagen Werk (trad. El libro de los pasajes). Edición de Rolf Tiedemann). Madrid: Ajal.

Bueno, E. (2007). La Tercera Misión de la Universidad. Revista Madri+D-Tribuna de Debate- Núm. 41marzo-abril 2007. Recuperado de http://www.madrimasd.org/revista/revista41/tribuna/tribuna2.asp

Campos, P. y Luceño, L. (2018). Las formas de la educación. Madrid: Dykinson.

Capone, F. y Lazzeretti, L. (2016). Fashion and city branding: An analysis of the perception of Florence as a fashion city. Journal of Global Fashion Marketing - Bridging Fashion and Marketing, Vol 7, № 3, 166-180.

Carreras, C. (1983). La Ciudad: Enseñanzas del fenómeno urbano. Madrid, España: Anaya.

Casariego, J. y Macías, G. (1908). Universidad y ciudad: la construcción del espacio universitario. Las Palmas de Gran Canaria, España: Universidad de Las Palmas de Gran Canaria.

Castro, M., Rodríguez, M. y Urteaga, E. (2016). Abrir las aulas: el vínculo entre docencia, investigación y vinculación comunitaria. Revista Brasileira de Educação, Vol 21, № 66, 737-758. Recuperado de https://www.scielo.br/scielo.php?pid=\$1413-24782016000300737\&script=sci_abstract\&tlng=es

Cubides, H., y Salinas, J. (2010). La ciudad como escenario de acción educativa de las organizaciones juveniles. Educación y Ciudad (18), 33-48. Recuperado de https://revistas.idep.edu.co/index.php/educacion-y-ciudad/article/view/167 
De Simone, L. (2012). La moda: hacia una comprensión de la sociedad de consumo en la ciudad moderna. En Márquez, F. (Ed.), Las ciudades de Georg Simmel. Lecturas Contemporáneas (pp.97-114). Santiago de Chile: Ediciones Universidad Alberto Hurtado.

Echeverría, J. (2011). Conde Duque. Espejo de la memoria. Madrid, España: Ayuntamiento de Madrid.

Figueras, P. (2007). Ciudades educadoras, una apuesta por la educación. Participación educativa, № 6. Ministerio de Educación y Ciencia, 22-27.

Finkelstein, J. (1996). Fashion. An introduction. Nueva York: New York University Press.

Franco, A. y Zabala, S. (2012). Los equipamientos urbanos como instrumentos para la construcción de ciudad y ciudadanía. Dearq 11, 8-13. Recuperado de https://www.redalyc.org/pdf/3416/341630320003.pdf

González, E. (2019). Matadero Madrid: ruina moderna, ciudad de las artes. Quaderns de L'institut Del Teatre. №44, 386-405.

Hernández Díaz, J.M. (2014). Los espacios de la universidad española. Una lectura histórica. CIANRevista de Historia de las Universidades, 17/1 (2014), 81-100.

Izquierdo, A. (2005). Ciudad. Probabilidad emergente de un organismo vivo. Una aproximación epistemológica a la relación universidad-ciudad en tanto problema filosófico contemporáneo. Desafíos, № 13, 206-238. Recuperado de https://revistas.urosario.edu.co/index.php/desafios/article/view/692

Johnson, M. L. (2015). The embodied meaning of architecture. Cambridge, MA, EE.UU.: The MIT Press.

Luigi, M. (1995). Via Tornabuoni. Il salotto di Firenze. Florencia, Italia: Loggia De' Lanzi Editore.

Martín, E. (2009). A propósito de Berlín (o desmontando a Ruttmann). Imaginarios sociales y representaciones urbanas en el cine documental. Biblio 3W. Revista bibliográfica de Geografía y Ciencias Sociales, 14(842). Recuperado de http://www.ub.edu/geocrit/b3w-842.htm

Mas, S. y Sabaté, J. (2013). Gestión del patrimonio industrial en la renovación de la ciudad: la experiencia de Terrassa 1959-2011. ACE: Architecture, City and Environment, 7(21), 11-36. DOI: http://dx.doi.org/10.5821/ace.v7i21.2582

Merckx, F., Notteboom, T. y Winkelmans, W. (2003). Spatial models of waterfront redevelopment: the tension between city and port revisited. Proceedings of IAME 2003 Conference, International Association of Maritime Economists, Busan, Korea, 267-85.

Nair, P., \& Fielding, R. (2005). The Language of School Design. Minneapolis. MN, EE.UU.: Designshare

Navascués P. (1971). Antonio López Aguado, arquitecto mayor de Madrid (1764-1831). Villa de Madrid, no 33, 84-89. Recuperado de https://dialnet.unirioja.es/servlet/articulo?codigo=5413326

Oliva, C. y Sánchez, M. (2016). Las universidades públicas de la Comunidad de Madrid: Sinergias Ciudad-Universidad en el área metropolitana de Madrid capital. En García, F., García, M. y Taborda, E. (Eds.), Ciudades creativas. IV Congreso Internacional, Tomo II, Asociación de comunicación y nuevas tecnologías (pp. 94-103). Madrid, España: Universidad Complutense de Madrid.

ACE, 15 (4.5) CC BY-ND 3.0 ES | UPC Barcelona, España | La ciudad como escenario de innovación docente. El caso de la pasarela urbana en las enseñanzas de Moda. DOI: http://dx.doi.org/10.5821/ace.15.45.9486 
Ortiz, S. (2013). Educación patrimonial en la Universidad. Estrategias para la valoración del patrimonio cultural urbano en el proceso de formación de los jóvenes. Praxis, Vol. 9, № 1, 18-24.

Ostrowska, D. (2017). Cosmopolitan Spaces of International Film Festivals: Cannes Film Festival and the French Riviera. Alphaville: Journal of Film and Screen Media, no. 14, Winter, 94-110. Recuperado de https://core.ac.uk/download/pdf/141229312.pdf

Pappacoda, L. (1987). Fashion Design in city requalification. Antwerp and its fashion hub. Venecia, Italia: Università Ca' Foscar.

Pérez, M. y González, D. (2010). Salir del aula: el papel de la ciudad en la educación. Tejuelo, no 9, 121135.

Pineau, P., Dussel, I. y Caruso, M. (2001). La escuela como máquina de educar: tres escritos sobre un proyecto de la modernidad. Buenos Aires, Argentina: Paidós Ibérica.

Pinkelton, C. y Burke, M. (2004). The Savannah College of Art and Design: Restoration of an Architectural Heritage. Charleston, SC, EE.UU.: Arcadia Publishing.

Radstrom, S. (2011). A Place $\neg$ Sustaining Framework for Local Urban Identity: An Introduction and History of Cittaslow. Italian Journal of Planning Practice. Vol. I, issue 1, 90-113.

Remy, J. (2012). Gran ciudad y pequeña ciudad: tensiones entre sociabilidad y estética en Simmel En Márquez, F. (Ed.), Las ciudades de Georg Simmel. Lecturas Contemporáneas (pp.21-54). Santiago de Chile: Ediciones Universidad Alberto Hurtado.

Riquelme-Quiñonero, MT.; Alpáñez Serrano, D.; Espeso-Molinero, P.; Ferrández Ferrer, A.; De Frutos Herranz, R.; Navarro Mondejar, R.; Peidro Blanes, J. y Ramos Rodríguez, A. (2019). Mediación cultural, sinergias entre Universidad y museo. En Roig-Vila, R. (Ed.), Memorias del Programa de Redes-/3CE de calidad, innovación e investigación en docencia universitaria. Convocatoria 2018-19 (pp.1515-1534). Alicante, España: Universidad de Alicante.

Silvera, A. y Sacker, J. (2013). Proyecto educativo de ciudad: desarrollo del ser social de cara a la vida global. Revista Logos, Ciencia \& Tecnología, vol. 4, núm. 2, 62-69.

Simmel, J. (1923). Filosofía de la moda. Revista de Occidente, Año I, no. 1, 44-47.

Williams, D. (2017) Fashion, the city, and the spectacle. En Egenhoefer, R.B. (Ed.) Routledge Handbook of Sustainable Design (pp. 281-294). Londres, Reino Unido: Routledge. 